\title{
The Future of Continuous Glucose Monitoring
}

\author{
Satish K. Garg, MD ${ }^{1,2}$ and Halis K. Akturk, MD ${ }^{1,2}$
}

$\mathbf{M}$ ORE THAN THREE decades ago, when self-monitoring of blood glucose (SMBG) was first made available, most people doubted its uptake by questioning "who, why, and when?" Debates were around about why patients would poke their fingers few times a day and moreover, what will they do with the data? Today, it is the standard of care and was successfully used in the Diabetes Complications and Control Trial especially in the intensive arm. ${ }^{1}$ Most of the recent data from the type 1 diabetes (T1D) Exchange show increased SMBG monitoring results in better reduction of A1c in patients with T1D. ${ }^{2}$

Similar criticism surrounds continuous glucose monitoring (CGM) now. The first available retrospective CGM system was MiniMed iPro ${ }^{\circledR}$ (nearly two decades ago) followed by the real-time display GlucoWatch ${ }^{\circledR}$ in the year 2000 for $12 \mathrm{~h}$ using reversed iontophoresis., ${ }^{3,4}$ The next decade saw significant advances in CGM technologies by the Navigator (Abbott), Dexcom short-term sensor (STS), Gen 4 and $5^{\circledR}$, and Medtronic Enlite ${ }^{\circledR}$ and Guardian $3^{\circledR}$. Most of the advances focused on improved accuracy where single digit mean absolute relative difference has become the standard, and in many instances, CGMs are now as accurate as SMBG.

The early adoption of CGM was slow as expected with any new technology innovation. More recent data show a rapid increase in adoption rate across the United States and Western Europe, in part, due to improved accuracy and better coverage by the payers. ${ }^{5}$ As the number of patients using CGM increases, one hopes that the cost will go down. In this supplement, Graham discussed the challenges in the global reimbursement of $\mathrm{CGM}^{6}$ In the future, CGM data will be available (currently only Dexcom Gen $5^{\circledR}$ ) on all mobile phones that use Bluetooth and insulin pumps without needing the data going through a receiver. Also, further advances in the technology will allow CGM to be used for 14 days without any calibration (factory calibration) or any need for an additional transmitter or receiver. After the 14-day use, the subject discards the whole CGM unit. As described by Hughes et al. in this supplement, once-daily calibrated real-time CGMs that have 10-day functional life may become available shortly. ${ }^{7}$

Currently, only FreeStyle Professional Libre (factory calibrated), flash glucose monitoring, is available in the US for
14 days for professional use. ${ }^{8}$ However, it is approved in Europe for personal use too. ${ }^{9}$ The flash glucose monitoring data are only available on demand and have no alarm feature. Please see the details of flash glucose monitoring in another supplement. ${ }^{10}$ It is also important to highlight that the future may see all CGM systems to be factory calibrated and data could be used to adjust insulin dose as a nonadjunctive device. Most patients do not use CGM as an adjunctive device to SMBG, and the Food and Drug Administration (FDA) recently approved Dexcom Gen $5^{\circledR}$ system data, which can be used as a nonadjunctive, except that it still needs calibration twice a day. ${ }^{11}$ Just like all patients with new-onset T1D get an SMBG meter today, we hope in the very near future, all patients with new-onset T1D will receive CGM. Forlenza et al. also emphasized challenges of the use of CGM in children and older adults in this supplement. ${ }^{12}$

The availability of CGMs has highlighted the deficiencies in following diabetes care based on A1c estimations. ${ }^{5}$ Glucose control measured by A1c values is a snapshot of overall glucose values for the past 1-3 months. It does not detect hypoglycemia or hyperglycemia on a day-to-day basis where patients need that information on a continual basis. The availability of CGM data has allowed patients and providers to not only improve glucose control but also reduce hypoglycemia and hyperglycemia across all ranges. ${ }^{13,14}$ This concept is further discussed in detail by Rodbard in this supplement. ${ }^{15}$ The CGM data can be summarized as glucose ranges (time in the range $70-180 \mathrm{mg} / \mathrm{dL}$ ) and time spent above and below the target. Late last year, the FDA held a meeting in Washington, DC where the discussion was about moving beyond A1c. ${ }^{16} \mathrm{We}$ hope the future will see time in range, above target range, and below target range as important tools to quantify glucose control like A1c on a day-to-day basis. Since A1c gives only a snapshot of overall glucose control, a new composite metric for the assessment of glucose control based on CGM data is explained by Hirsch et al. in this supplement. ${ }^{17}$

Another advantage of CGM use is alerts and alarms where subjects can be alarmed for impending hypoglycemia and hyperglycemia based on the rate of change of glucose, and thus patients can act accordingly. ${ }^{18,19}$ Using CGM may have great

\footnotetext{
${ }^{1}$ School of Medicine, University of Colorado Denver, Aurora, Colorado.

${ }^{2}$ Barbara Davis Center for Diabetes, Aurora, Colorado.
} 
benefits for high-risk individuals such as pregnant patients with T1D (off-label use). Improved maternofetal outcomes are defined in detail by Polsky and Garcetti in this supplement. ${ }^{20}$

Significant advances with CGM and insulin pumps have allowed CGM data to be used to drive insulin delivery. ${ }^{21}$ The first such system hybrid closed loop, also called as artificial pancreas by the FDA, was approved in September $2016 .^{22}$ It was first made available in late March 2017 in the United States. Castle et al. highlighted the future of automated insulin delivery systems based on CGM performance, form factor, and adaptability in this supplement. ${ }^{23}$ Since all insulin-requiring patients with diabetes will not go on to pump therapy, it is important to look into the needs of the vast majority of multiple daily injections (MDI) patients ( $>90 \%$, globally). Improved outcomes in patients with T1D who use MDI with CGM are elaborated by McGill and Ahmann in this supplement. ${ }^{24}$ Future research may include CGM data display on mobile devices and insulin pens. The mobile devices may have applications (Apps) for guiding patients on insulin dose. ${ }^{25,26}$

We feel the future is bright for people with diabetes. We want to sincerely thank Dexcom for sponsoring this supplement, and we hope you all find this supplement useful for your clinical practice.

\section{References}

1. The Diabetes Control and Complications Research Group: The effect of intensive treatment of diabetes on the development and progression of long-term complications of insulin-dependent diabetes mellitus. N Engl J Med 1993; 329:997-1036.

2. Miller KM, Foster NC, Beck RW, et al.: Current state of type 1 diabetes treatment in the U.S.: updated data from the T1D Exchange clinic registry. Diabetes Care 2015;38:971-978.

3. Garg SK, Potts RO, Ackerman NR, et al.: Correlation of fingerstick blood glucose measurements with GlucoWatch Biographer results in young subjects with type 1 diabetes. Diabetes Care 1999;22:1708-1714.

4. Tamada JA, Garg S, Jovanovic L, et al.: Non-invasive glucose monitoring: comprehensive clinical results. JAMA 1999;282:1839-1844.

5. Mazze RS: Acceptance of FGM or CGM in clinical decision-making and patient preference: where do we go from here? Diabetes Technol Ther 2017;19:142-144.

6. Graham C: Continuous glucose monitoring and global reimbursement: an update. Diabetes Technol Ther 2017;19: (Suppl 3):S-60-S-66.

7. Hughes J, Welsh JB, Bhavaraju NC, et al.: Stability, accuracy, and risk assessment of a novel subcutaneous glucose sensor. Diabetes Technol Ther 2017;19(Suppl 3):S-21-S-24.

8. US Food and Drug Administration: Approval Order: Freestyle Libre Pro Flash Glucose Monitoring System. PI50021. Department of Health and Human Services; Silver Spring, MD, 2016.

9. European Economic Area: Approval: Freestyle Libre Flash Glucose Monitoring System CE Mark (Conformite Europeenne). Abbott Laboratories Ltd. Press release: Abbott receives CE mark for Freestyle Libre. September 3, 2014.

10. Garg SK, Akturk HK: Flash glucose monitoring: the future is here. Diabetes Technol Ther 2017;19(Suppl 2):S-1-S-3.

11. US Food and Drug Administration: Approval Order: Dexcom G5 Mobile Continuous Glucose Monitoring System. PI20005. Silver Spring, MD: Department of Health and Human Services, 2016.
12. Forlenza GP, Argento NB, Laffel LM: Practical considerations on the use of continuous glucose monitoring in pediatrics and older adults and nonadjunctive use. Diabetes Technol Ther 2017;19(Suppl 3):S-13-S-20.

13. Fonseca VA, Grunsberger G, Anhalt H, et al.: Continuous glucose monitoring: a consensus statement by the American Association of Clinical Endocrinologists and American College of Endocrinology. Endocr Pract 2016;22:1008-1021.

14. Ellis SL, Bookout T, Garg SK, Izuora KE: Use of continuous glucose monitoring to improve diabetes mellitus management. Endocrinol Metab Clin North Am 2007; 36(Suppl 2):47-68.

15. Rodbard D: Continuous glucose monitoring: a review of recent studies demonstrating improved glycemic outcomes. Diabetes Technol Ther 2017;19(Suppl 3):S-25-S-37.

16. US Food and Drug Administration: Public Workshop: Diabetes Outcome Measures Beyond Hemoglobin A1c (HbA1c). Silver Spring, MD: Center for Drug Evaluation and Research, 2016.

17. Hirsch IB, Balo AK, Sayer K, et al. A simple composite metric for the assessment of glycemic status from continuous glucose monitoring data: implications for clinical practice and the artificial pancreas. Diabetes Technol Ther 2017;19(Suppl 3):S-38-S-48.

18. Kropff J, DeVries JH: Continuous glucose monitoring, future products, and update on worldwide artificial pancreas projects. Diabetes Technol Ther 2016;18(Suppl 2):S253-S263.

19. Garg SK, Weinzimer SA, Tamborlane WV, et al. Glucose outcomes with the in-home use of a hybrid closed-loop insulin delivery system in adolescents and adults with type 1 diabetes. Diabetes Technol Ther 2017;19:155-163.

20. Polsky S, Garcetti R: CGM, pregnancy, and remote monitoring. Diabetes Technol Ther 2017;19(Suppl 3):S-49-S-59.

21. Aleppo G, Ruedy KJ, Riddlesworth TD, et al.; REPLACEBG Study Group. REPLACE-BG: a randomized trial comparing continuous glucose monitoring with and without routine blood glucose monitoring in well-controlled adults with type 1 diabetes. Diabetes Care 2017; pii: dc162482.

22. US Food and Drug Administration: Letter of Approval: Tamar Jaghasbanian, Regulatory Affairs, Medtronic MiniMed. Department of Health and Human Services, Silver Spring, MD, 2016.

23. Castle JR, DeVries JH, Kovatchev B: Future of automated insulin delivery systems. Diabetes Technol Ther 2017; 19(Suppl 3):S-67-S-72.

24. McGill JB, Ahmann A: Continuous glucose monitoring with multiple daily insulin treatment: outcome studies. Diabetes Technol Ther 2017;19(Suppl 3):S-3-S-12.

25. Shah VN, Garg SK: Managing diabetes in the digital age. Clin Diabetes Endocrinol 2015;16:1-7.

26. Shah VN, Shoskes A, Tawfik B, Garg SK: Closed-loop system in the management of diabetes: past, present and future. Diabetes Technol Ther 2014;16:477-490.

Address correspondence to: Satish K. Garg, MD

Professor of Medicine and Pediatrics Barbara Davis Center for Diabetes University of Colorado Denver 1775 Aurora Court, A140 Aurora, CO 80045

E-mail: satish.garg@ucdenver.edu 